\title{
471577 - PATIENT SATISFACTION IN AMBULATORY ANESTHESIA: A SYSTEMATIC REVIEW
}

\author{
Pratamaporn Chanthong, M.D., Amir Abrishami, M.D., Jean Wong, M.D., \\ F.R.C.P.C, Frances Chung, M.D., F.R.C.P.C. \\ Anesthesia, Toronto Western Hospital, University Health Network, University of \\ Toronto, Toronto, ON, Canada
}

Introduction: Patient satisfaction has become an important component of quality improvement in healthcare. Traditional outcomes (e.g. mortality or morbidity) fail to address issues that may be of greater significance in ambulatory anesthesia such as quality of life and patient satisfaction. However, these new outcomes are difficult to measure due to their subjective and complex psychological construct ${ }^{1}$. We conducted a systematic review to evaluate instruments to measure patient satisfaction with ambulatory anesthesia.

Methods: A systematic literature search of The Cochrane Library, MEDLINE, EMBASE, CINAHL, HAPI, PsycINFO and Dissertation Abstracts was performed to identify studies on questionnaires evaluating patient satisfaction after ambulatory anesthesia. We included the articles that used multi-item questionnaires and the questionnaires were assessed with the strategy of psychometric questionnaire construction $^{1}$, validity, reliability and acceptability.

Results: We scanned 115 articles yielded by our search strategy. Eleven articles eventually were included in the study in which multi-item questions were used to evaluate patient satisfaction regarding ambulatory anesthesia (Table-1). Eight articles used self-administered questionnaire, the other three used interviewed methods. The format of the questionnaires are point-scale (8 articles), yes/no (2 articles) and ranked order ( 1 article) questionnaire. The most common dimensions evaluated by the questionnaires were pain and physical discomfort, patient information about anesthesia care and emotional support. Five studies validated their questionnaires by evaluating content and construct validity and/or test of reliability (e.g. internal consistency or testretest). There are two instruments, IOWA Satisfaction with Anesthesia Scale (ISAS) and Evaluation du Vecu de I'Anesthesie Generale (EVAN-G) that fulfilled our criteria for the development of psychometrically constructed, multi-item questionnaires. Only one instrument, ISAS, was specifically designed for ambulatory anesthesia; however, this instrument was developed only for monitored anesthesia care patients.

Discussion: In a large number of trials, patient satisfaction regarding anesthesia in ambulatory settings have been evaluated using only one or two questions or questionnaires that did not test reliability and validity. Only a few studies have developed questionnaires with rigorous psychometric methods to measure patient satisfaction with anesthesia care. Further study should be conducted to develop standardized instruments to measure this outcome.

References: 1. Anesth Analg 1998 87: 1089-98

Table 1: Psychometric properties of the questionnaires 


\begin{tabular}{|c|c|c|c|c|c|}
\hline Study ID & Item generation & Pilot testing & Validity & Reliability ${ }^{\dagger}$ & $\begin{array}{c}\text { Response } \\
\text { rate }\end{array}$ \\
\hline $\begin{array}{c}\text { Auquier } \\
\text { (EVAN-G) }\end{array}$ & Yes & Yes & Yes & $0.73-0.91$ & $89.4 \%$ \\
\hline Brown & No & No & No & No & $75.9 \%$ \\
\hline Carro & No & No & No & No & $100 \%$ \\
\hline $\begin{array}{c}\text { Dexter } \\
\text { ISAS) }\end{array}$ & Yes & Yes & Yes & 0.80 & $92 \%$ \\
\hline Dodds & No & No & No & No & $97.5 \%$ \\
\hline Fleisher & No & No & No & 0.62 & $61.4 \%$ \\
\hline Fung & Yes & No & No & $0.86-0.94$ & $26 \%$ \\
\hline $\begin{array}{c}\text { Heather } \\
\text { (WCCS }\end{array}$ & Yes & No & No & No & $100 \%$ \\
\hline Martin & No & No & No & test-retest & $100 \%$ \\
\hline Pestey & No & No & No & No & $54 \%$ \\
\hline Preble & & & & $71 \%$ \\
\hline
\end{tabular}

$\dagger:$ Cronbach $\alpha$, ‡: Wascana Client-Centered Care Survey 